Document downloaded from:

http://hdl.handle.net/10251/166456

This paper must be cited as:

Palumbo, F.; Andreu Ros, MI.; Brunetti, M.; Schmallegger, M.; Gescheidt, G.; Neshchadin, D.; Miranda Alonso, MÁ. (2019). Hydrogen Abstraction from the C15 Position of the Cholesterol Skeleton. The Journal of Organic Chemistry. 84(23):15184-15191. https://doi.org/10.1021/acs.joc.9b02181

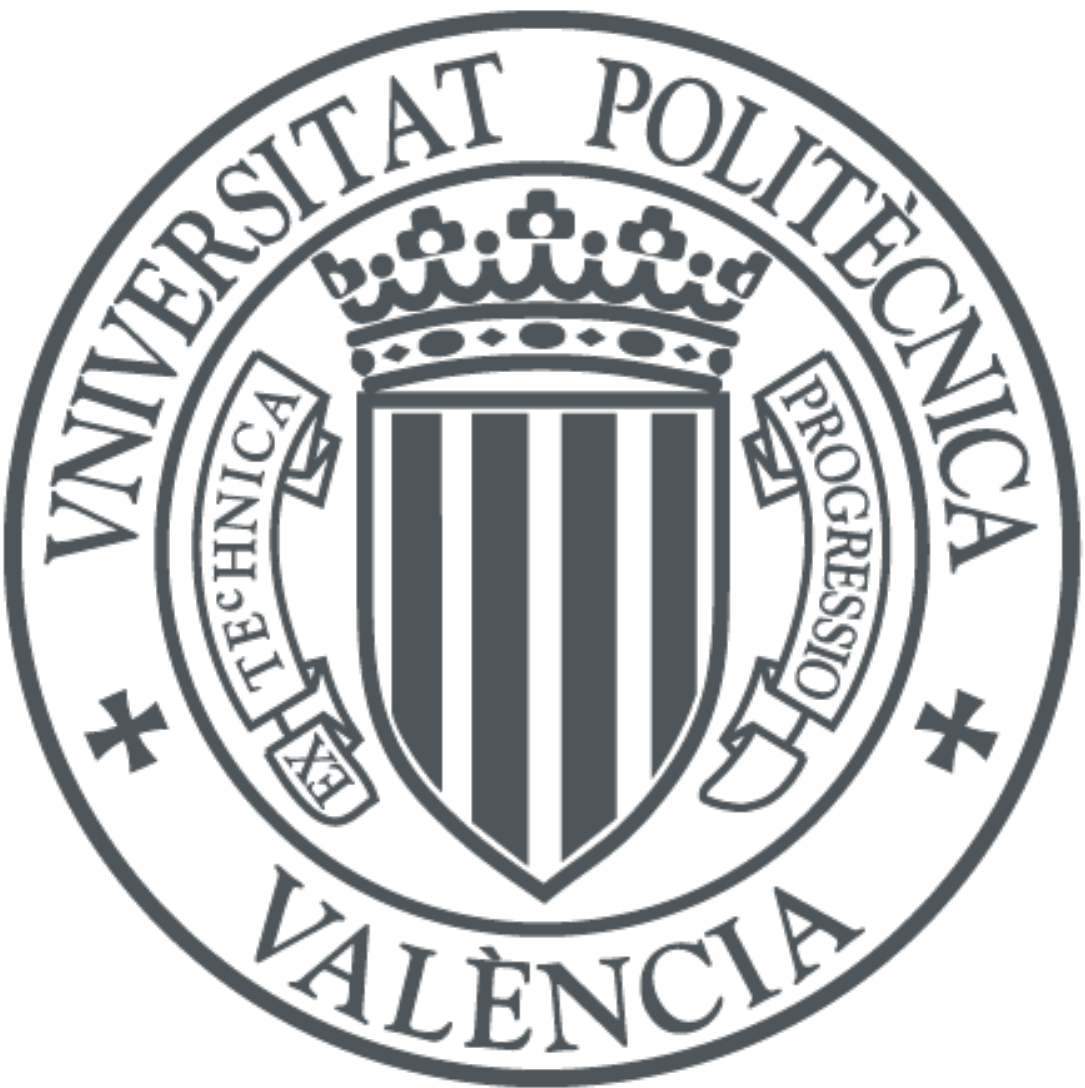

The final publication is available at

https://doi.org/10.1021/acs.joc.9b02181

Copyright American Chemical Society

Additional Information 


\section{Hydrogen abstraction from the C15 position of the cholesterol}

\section{skeleton}

3 Fabrizio Palumbo, ${ }^{\mathrm{a}}$ Inmaculada Andreu, ${ }^{* a, c}$ Maria Brunetti, ${ }^{\mathrm{a}}$ Max Schmallegger, ${ }^{\mathrm{b}}$ Georg

4 Gescheidt, ${ }^{b}$ Dmytro Neshchadin, ${ }^{* b}$ and Miguel A. Miranda*a,c

5

6 a Instituto de Tecnología Química UPV-CSIC, Universitat Politècnica de València, Camino

7 de Vera s/n, 46022 Valencia, Spain. E-mail:mmiranda@qim.upv.es

$8 \mathrm{~b}^{\mathrm{b}}$ Institute of Physical and Theoretical Chemistry, Graz University of Technology, NAWI

9 Graz, Stremayrgasse 9/I, 8010 Graz, Austria. E-mail: neshchadin@tugraz.at

10 c Unidad Mixta de Investigación UPV-Instituto de Investigación Sanitaria (IIS) La Fe,

11 Hospital Universitari i Politècnic La Fe, Avenida de Fernando Abril Martorell 106, 46026

12 Valencia, Spain. E-mail: iandreur@qim.upv.es

14 Abstract graphic

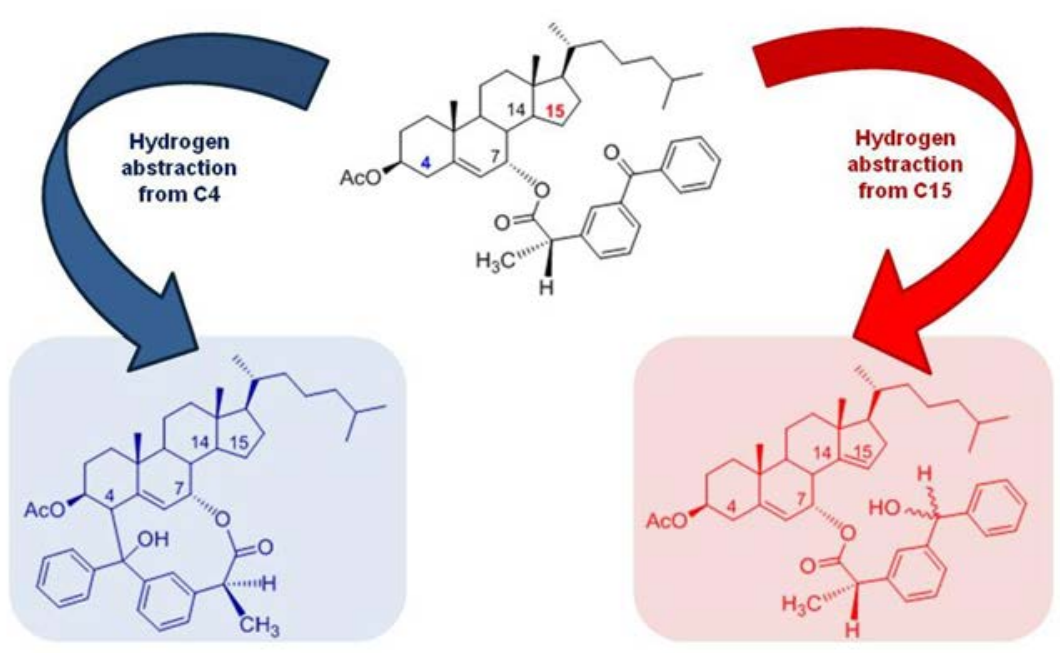


17 Cholesterol $(\mathrm{Ch})$ is an integral part of cell membranes, where it is prone to oxidation. In humans, oxidation of $\mathrm{Ch}$ is commonly linked to various pathologies like Alzheimer's, atherosclerosis and even cancer, which proceed via mechanisms involving enzymatic and free radical pathways. The latter begin with hydrogen abstraction ( $\mathrm{HA}$ ) from $\mathrm{Ch}$ by a reactive free radical. It has been established that the most efficient $\mathrm{HA}$ from $\mathrm{Ch}$ occurs at $\mathrm{C7}$, although HA from C4 by peroxyl radicals has recently been observed. Conversely, HA from Ch positions other than the thermodynamically preferred C7 or C4 has never been reported. We have designed a Ch derivative where a benzophenone moiety is linked to $\mathrm{C} 7$ by a covalent bond. This mirrors a specific orientation of $\mathrm{Ch}$ within a confined environment. Product analysis and time-resolved spectroscopic studies reveal an unprecedented $\mathrm{HA}$ from $\mathrm{C} 15$, which is a thermodynamically unfavorable position. This indicates that a specific topology of reactants is crucial for the reactivity of $\mathbf{C h}$. The relative orientation of the reactants can also be relevant in biological membranes, where Ch, polyunsaturated fatty acids (PUFA) and numerous oxidizing species are confined in highly restricted and anisotropic environments.

\section{Introduction}

Cholesterol (Ch) is one of the most important building blocks of eukaryotic cells. This molecule carries out multiple functions in cell membranes: it controls membrane fluidity and permeability, composing rigid rafts to support various membrane proteins. Moreover, Ch plays a significant role in the biosynthesis of numerous hormones, vitamin D, and bile acids. Cholesterol is also one of the main targets for oxidation in cell 
membranes. In humans, oxidation of $\mathrm{Ch}$ is commonly linked to various pathologies like Alzheimer's, atherosclerosis and even cancer. ${ }^{1-6}$ Such detrimental processes proceed via distinct mechanisms, including enzymatic and free radical pathways. The latter begin with hydrogen abstraction ( $\mathrm{HA}$ ) from $\mathrm{Ch}$ by a reactive free radical (Scheme 1 ) primarily forming a Ch-derived radical. ${ }^{7}$ The follow-up reaction with molecular oxygen leads to peroxyl radicals that, in turn, can abstract hydrogen from another $\mathbf{C h}$ molecule, polyunsaturated fatty acids, or antioxidants. ${ }^{8}$ Oxidation via radicals in vivo may be caused by reactive oxygen species but also various photo-sensitive drugs like ketoprofen that are capable of abstracting hydrogen atoms from biological targets like polyunsaturated fatty acids (PUFA) and DNA inducing potentially damaging chemical reactions. Indeed, ketoprofen ${ }^{9}$ (2-(3-benzoylphenyl)propanoic acid), which is widely used as non-steroidal anti-inflammatory drug (NSAID) with analgesic and antipyretic effects, is able to absorb UVA light that can penetrate the middle layer of skin (the dermis), inducing frequently phototoxic and photoallergic effects in patients. ${ }^{10,11}$

The primary HA from a steroid skeleton by photoexcited benzophenone has been largely investigated by Breslow and coworkers many years ago. ${ }^{12,13}$ They have synthesized saturated dihydrosteroid derivatives (e.g. $3 \alpha$-cholestanol) comprising a benzophenone moiety. Based on product analysis of irradiated solutions, CD spectra, phosphorescence lifetime, and molecular models, they could show that HA is directed mainly by the topology of the steroid/benzophenone dyads. In contrast to dihydrosteroids, Ch carries a double bond at C5-C6. In this latter case, it is well established that the most efficient hydrogen abstraction occurs from $\mathrm{C} 7$ and $\mathrm{C} 4 .{ }^{14}$ Evidently, the bond dissociation energies (BDE) of the allylic hydrogens, $\mathrm{C} 7-\mathrm{H}$ and $\mathrm{C} 4-\mathrm{H}$ are the lowest in the steroid core of $\mathbf{C h}$. Therefore such a selectivity of hydrogen transfer can be explained by thermodynamic 
control. However, in complex and inhomogeneous environments like membranes, even

63

64

65

66

67

68

69

70

71

72

75

76

77

78

79

80

81

82

75

small molecules can be forced to a confined orientation. ${ }^{15}$ This may cause entropic

factors to become dominant. Farez et al. detected $15 \alpha$-hydroxycholestene $(15-\mathrm{HC})$ in patients with secondary progressive multiple sclerosis (SPMS). ${ }^{16}$ This 15 -oxysterol can be, in principle, formed as a result of an initial HA from $\mathrm{C} 15$ of cholesterol in cell membranes. Although the findings of Farez et al. are under debate, ${ }^{17}$ it is important to find out whether a thermodynamically unfavorable HA from Ch can be overruled by topological confinement. In addition, taking into account that the steroidal skeleton, as well as $\mathrm{C}-\mathrm{H}$ functionalization, have attracted the attention of synthetic chemists for decades, the present work is of considerable interest in the field of basic organic chemistry, since it is focused on selective activation of stronger $\mathrm{C}-\mathrm{H}$ bonds in the presence of weaker ones. ${ }^{18,19}$
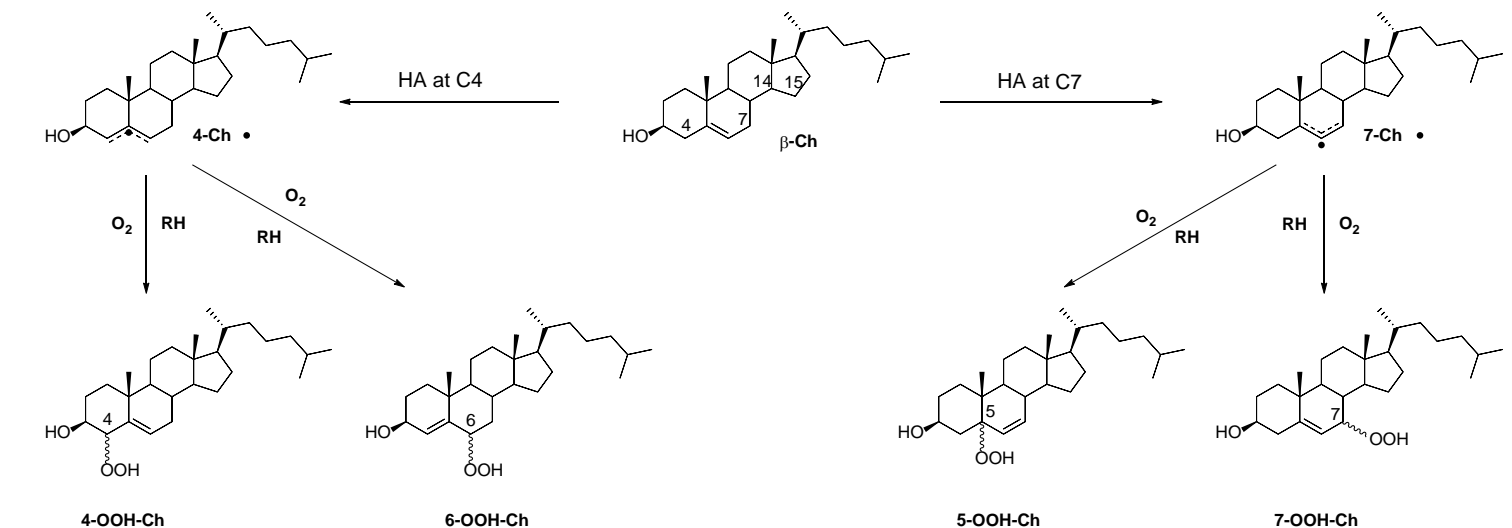

7
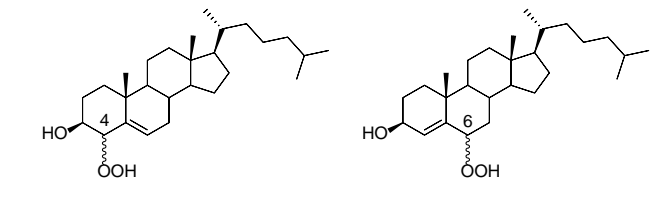

4-OOH-Ch

6-OOH-Ch

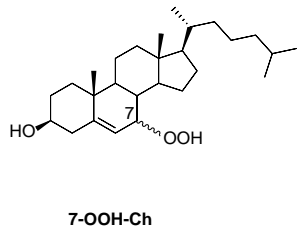

Scheme 1. Free radical oxidation of Cholesterol

We have shown that HA by the photo-excited triplet state of ketoprofen from cholesterol's core is predominantly controlled by entropic factors like the spatial 
arrangement of reactants rather than by thermodynamic properties. ${ }^{20}$ The question is

84

whether topology is a decisive factor for the selectivity of HA reactions in steroids, and in this context we have designed and synthesized derivatives $\mathbf{1}$ and $\mathbf{2}$. In these model systems, the benzophenone fragment serves as a selective, photo-triggered intramolecular hydrogen-abstracting agent with the reaction at $\mathrm{C} 7$ being prevented by steric strain and conformational restrictions. It is our aim to shed light onto the role of topology/entropy for the selectivity of the HA reaction. In a first step, steady-state UV irradiation and product analysis provides access to the photo-induced conversions. To avoid artifacts caused by undesired follow-up reactions of steady-state photolysis, we have applied time-resolved methodology for substantiating the photo induced reaction (Figure 1). To this end, we have utilized Laser Flash Photolysis (LFP) and Time-Resolved Chemically Induced Dynamic Nuclear Polarization (TR-CIDNP).

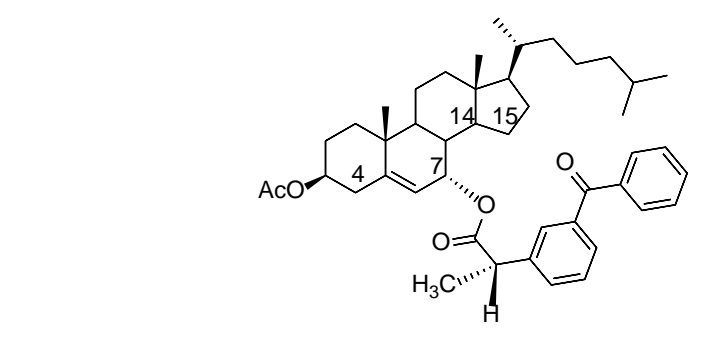

1

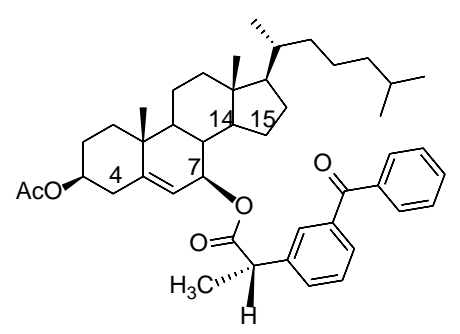

2

Figure $\mathbf{1}$ Chemical structures of diastereomeric dyads $\mathbf{1}$ and $\mathbf{2}$

\section{Results and discussion}

We have arranged the presentation of our results in two separate sections, one reporting on the photophysical/photochemical, the other on NMR/CIDNP-based investigations supported with quantum mechanical calculations. 
108 The diastereoisomeric esters $\mathbf{1}$ and $\mathbf{2}$ were prepared from acetylcholesterol (acetylCh) and (S)- ketoprofen ((S)-KP) following standard procedures ${ }^{21}$ (see details in

110 Supplementary Information). Steady state irradiations of $\mathbf{1}$ and $\mathbf{2}$ were carried out in

111 dichloromethane solutions $\left(c a .3 .5 \times 10^{-3} \mathrm{M}\right)$ under a nitrogen atmosphere, with a 400

112 W high-pressure mercury lamp as the light source. Even a long-term irradiation (8 hours)

113 of dyad 2 did not lead to any products. In contrast, dyad 1 reacted readily yielding

114 photoproducts 3 and $\mathbf{4}$ in similar quantities. Both $\mathbf{3}$ and $\mathbf{4}$ can only be formed via 115 intramolecular HA by the excited triplet state of the benzophenone moiety from carbons

116 C4 and C15 (or C14) of the steroid core. The overall photoreduction quantum yield for 117 dyad 1 was determined using a related compound (S)-KP-3 $\alpha$-Ch as actinometer ${ }^{22}$ and its 118 value was found to be 0.43 (0.22 and 0.21 for the formation of photoproducts 3 and 4 , 119 respectively). Scheme 2 shows a likely reaction mechanism. Structural differences 120 between $\mathbf{1}$ and $\mathbf{2}$ that led to such a dissimilar reactivity will be discussed later. 


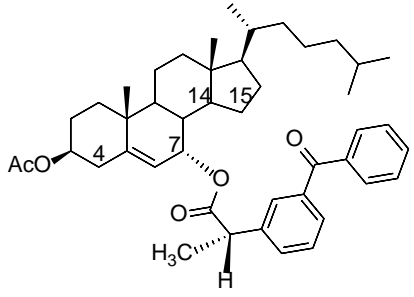

1

1. $h n$ / $\mathrm{N}_{2}$ 2. ISC

31

from C4 cular HA from C4

Intramolecular $\mathrm{HA}$
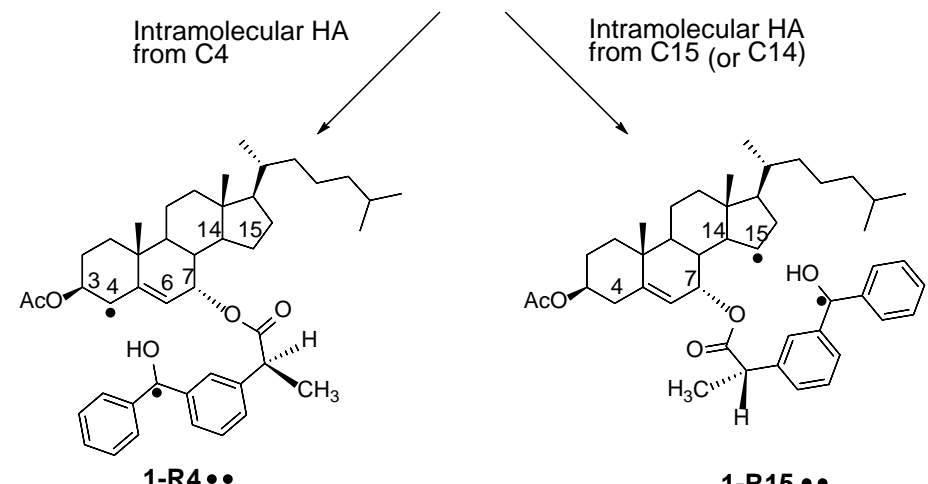

1-R15 • •
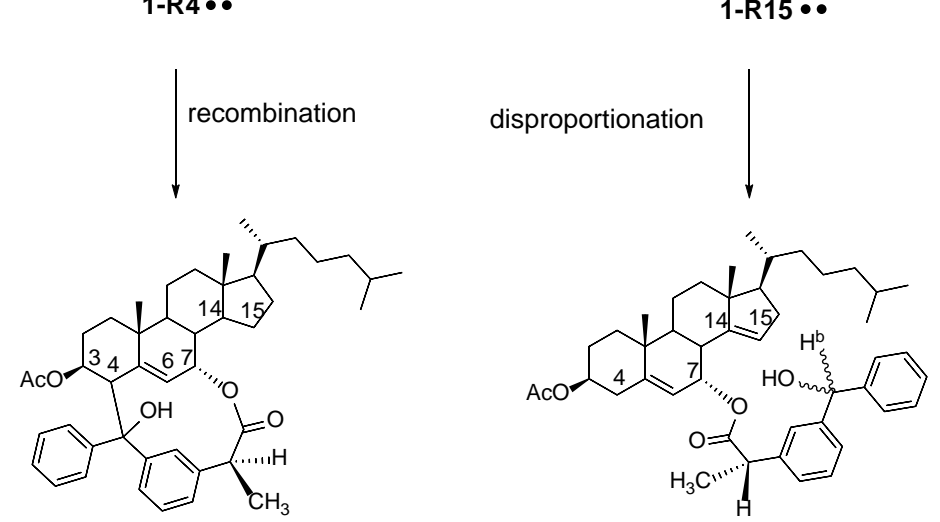

diastereomeric mixture 4 (25\%)

123 Photo-excitation of 1 leads to its triplet excited state, which is confined to the

124 benzophenone substituent and can abstract hydrogen atoms from the steroid fragment

of the molecule. Hydrogen abstraction from the position $\mathrm{C} 4$ of 1 results in biradical 1-

$\mathbf{R 4} \bullet \bullet$, subsequent recombination of the two radical centers in $\mathbf{1 - R 4} \bullet \bullet$ yields 

from C15 (C14).

We have established the structures of $\mathbf{3}$ and $\mathbf{4}$ unambiguously based on their NMR $\left({ }^{1} \mathrm{H}\right.$, ${ }^{13} \mathrm{C}, \mathrm{HSQC}$ and NOESY) and mass spectra. In particular, NOESY experiments of photoproduct 3 provided the stereochemistry of the new stereogenic center at C4 generated upon photocyclization. The most relevant interaction was found between the allylic proton at $\mathrm{C} 4$ and the hydrogen atoms of the phenyl group. Moreover, it should be noted that no NOE effect was found between the hydrogens at C4 and C3; this indicates that both protons are in a trans configuration (Figure 2).
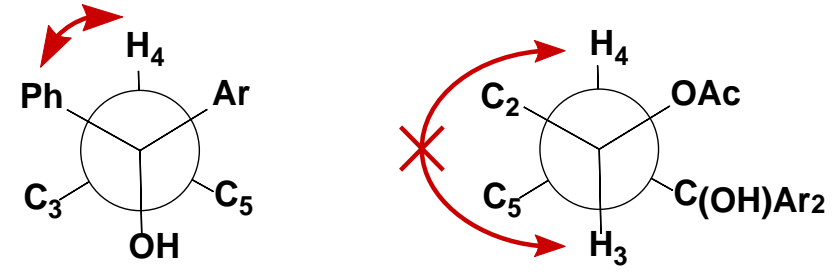

Figure 2. NOE interactions in 3

To gain insight into the photochemical processes at a shorter time scale, dyads $\mathbf{1}$ and $\mathbf{2}$ were probed by LFP $\left(\lambda_{\text {exc }}=355 \mathrm{~nm}\right)$ in dichloromethane solutions, under an inert atmosphere. The transient absorption spectrum of dyad $\mathbf{1}$, obtained $0.3 \mu$ s after the laser pulse (Figure 3), showed the exclusive presence of the benzophenone-based triplet excited state with a characteristic maximum absorption at $\lambda_{\max }=525 \mathrm{~nm}$. It was not possible to detect biradicals $\mathbf{1 - R 4} \bullet \bullet$ and $\mathbf{1 - R 1 5} \bullet \bullet$ (or $\mathbf{1 - R 1 4 \bullet \bullet )}$ ) on the microsecond time scale because their steady state concentrations are negligible due to rapid follow-up reactions. This is borne out by the observation that for dyad $\mathbf{2}$, which does not display intramolecular follow-up reactions, the ketyl radical $\left(\lambda_{\max }=545 \mathrm{~nm}\right)$ was observed as a 
result of a slow HA from the solvent, in addition to the triplet species. Kinetic analysis of decay traces allowed determining the triplet lifetimes $\left(\tau_{T}\right)$ of $\mathbf{1}\left(\tau_{\mathrm{T}}=0.60 \mu \mathrm{s}\right)$ and $\mathbf{2}\left(\tau_{\mathrm{T}}=\right.$ $1.67 \mu \mathrm{s})$. The latter matched the $\tau_{\top}$ value of the reference $(\mathbf{S})-\mathbf{K P}$ in dichloromethane. ${ }^{19}$ The intramolecular quenching rate constant (i.e. the upper limit of the rate constant of intramolecular $\mathrm{HA}$ ) can be calculated using triplet lifetimes: $k_{\text {iq }}=1 / \tau_{i}-1 / \tau_{0}$, where $\tau_{\text {i }}$ and $\tau_{0}$ are triplet lifetimes of dyad and reference compound $\left((S)-K P, \tau_{0}=1.6 \mu \mathrm{s}\right)$ correspondingly. For dyad 1 the upper limit is $1.07 \times 10^{6} \mathrm{~s}^{-1}$ for either $\mathrm{H}$ atoms at $\mathrm{C} 4$ and C15 (or C14). This strongly indicates that under UV irradiation 1 undergoes intramolecular hydrogen abstraction that is in full agreement with the results of product analysis after the longer irradiation times. The $k_{\text {iq }}$ obtained for 1 was found to be one order of magnitude lower than that determined for the intramolecular process in compounds containing benzophenone and 1,4 cyclohexadienes as hydrogen donors. ${ }^{23}$

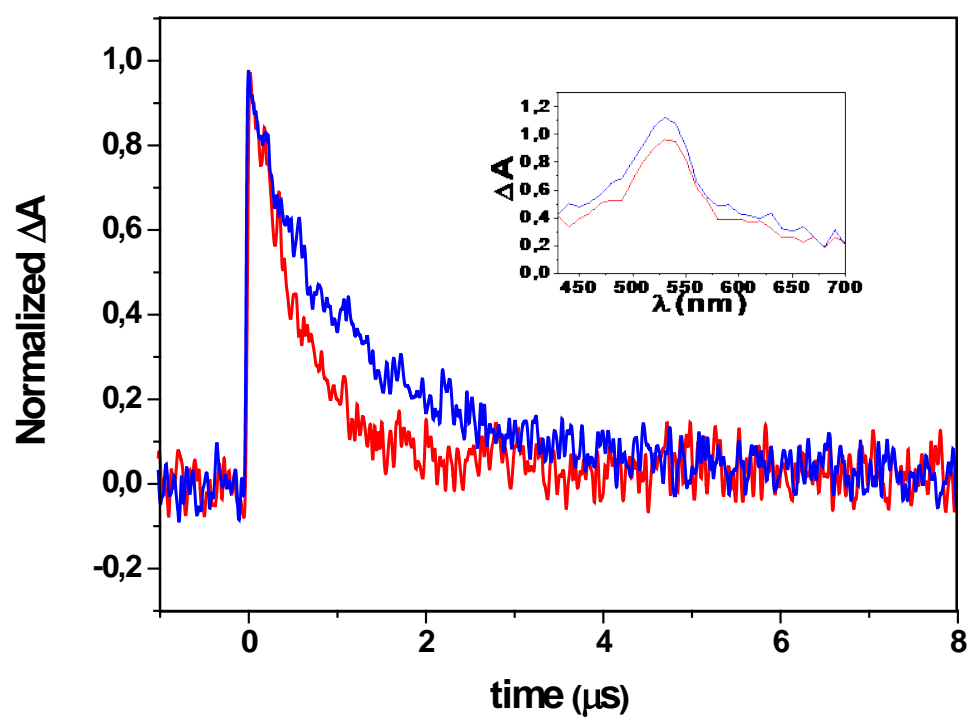

Figure 3. Normalized transient decays for $\mathbf{1}$ (red) and $\mathbf{2}$ (blue) monitored at $620 \mathrm{~nm}$ in $\mathrm{CH}_{2} \mathrm{Cl}_{2}$. Insert: 
Photo-CIDNP is a powerful NMR-based method to follow reactions based on the initial formation of radical (ion) pairs. These radical pairs react via pathways that depend on the electron spin states of the reaction partners. ${ }^{24,25}$ Since nuclear spin states are coupled to the electron spins, this spin-dependent reactivity leads to non-Boltzmann distributions of nuclear spin states. According to the long lifetimes of the non-Boltzmann populated nuclear states the NMR spectra of the products based on the primary radical pair indicate strongly enhanced (up to factor $10^{6}$ ) emissive ('enhanced emission') or absorptive ('enhanced absorption') signals. The intensity of the NMR signals can be translated into the structure of the intermediate free radicals. Photo-CIDNP can be performed in a time-resolved fashion also revealing kinetic information on free radical reactions. ${ }^{26}$

Here we used TR photo-CIDNP in combination with quantum mechanical calculations to distinguish between reaction pathways and intermediate free radicals formed by 1 after photo-excitation in different solvents.

Photo- ${ }^{1} \mathrm{H}$ CIDNP and ${ }^{1} \mathrm{H}$ NMR spectra of $\mathbf{1}$ in dichloromethane together with selected signal assignments are shown in Figure 4. The experimental design guarantees the suppression of background (equilibrium) NMR signals in CIDNP spectra, thus only pure to aliphatic protons in the steroid core $(\mathrm{S}, 0-2.5 \mathrm{ppm})$ and aromatic protons of the benzophenone moiety (BP, $7-8 \mathrm{ppm}$ ). This denotes that in the intermediate free 
191 radicals both steroid and benzophenone parts carry significant unpaired electron spin

192 density. The NMR transitions of the individual protons in the S and BP groups (Figure 4)

193 severely overlap with each other and are difficult to be analyzed further; however, there

194 are two characteristic polarizations in the CIDNP spectrum of 1 that can bring forth

195 additional information on the structure of reacting free radicals or biradicals.

196 Polarizations at 5.24 ppm ('enhanced emission') and 5.82 ppm ('enhanced absorption')

197 are unambiguously assigned to protons $\mathrm{H} 15$ and $\mathrm{Hb}$ in photoproduct 4 (Scheme 2, Figure

198 4). Additionally, two small polarizations are present at $3.1 \mathrm{ppm}$ ('enhanced absorption').

199 They presumably belong to the proton at C4 in recombination product 3. 


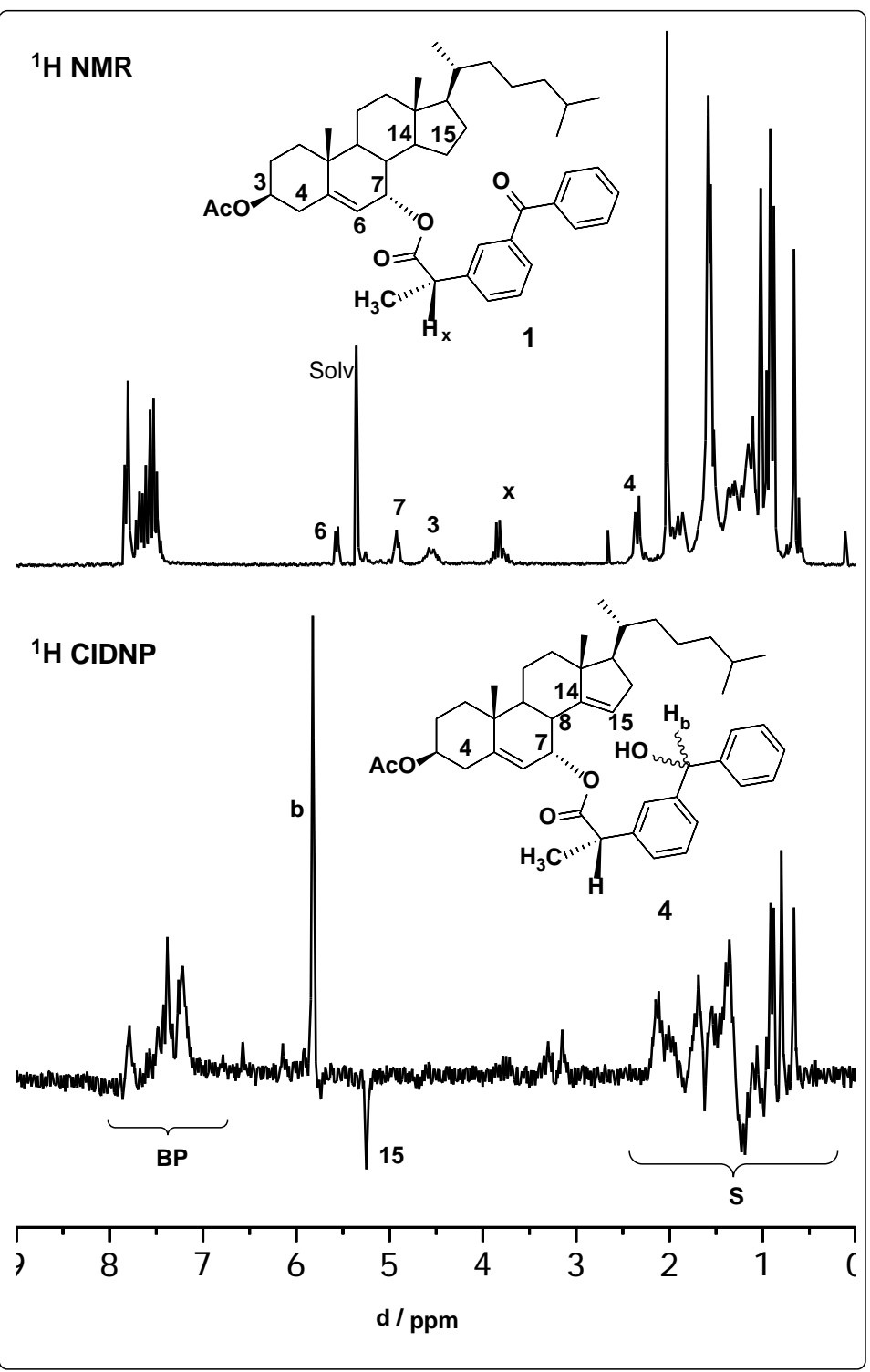

Figure 4. ${ }^{1} \mathrm{H}$ NMR (upper trace) and TR-CIDNP (bottom trace) spectra of 1 in dichloromethane- $d_{2}$. CIDNP spectrum is recorded $2 \mu$ s after the laser flash ( $8 \mathrm{~ns}, 355 \mathrm{~nm}$ )

The magnitude of the CIDNP polarizations strongly depends on a hyperfine coupling constant of corresponding nuclei in free radicals/biradicals where these polarizations were generated. ${ }^{27,28}$ The very short time-delay between laser flash and observing radiofrequency pulses allows observation of almost exclusively CIDNP polarizations that are stored in a cage product formed immediately from the initial radical pair. Thus, the lines

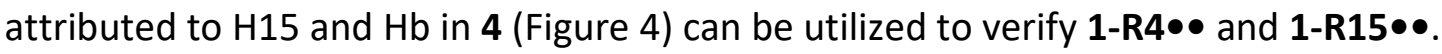




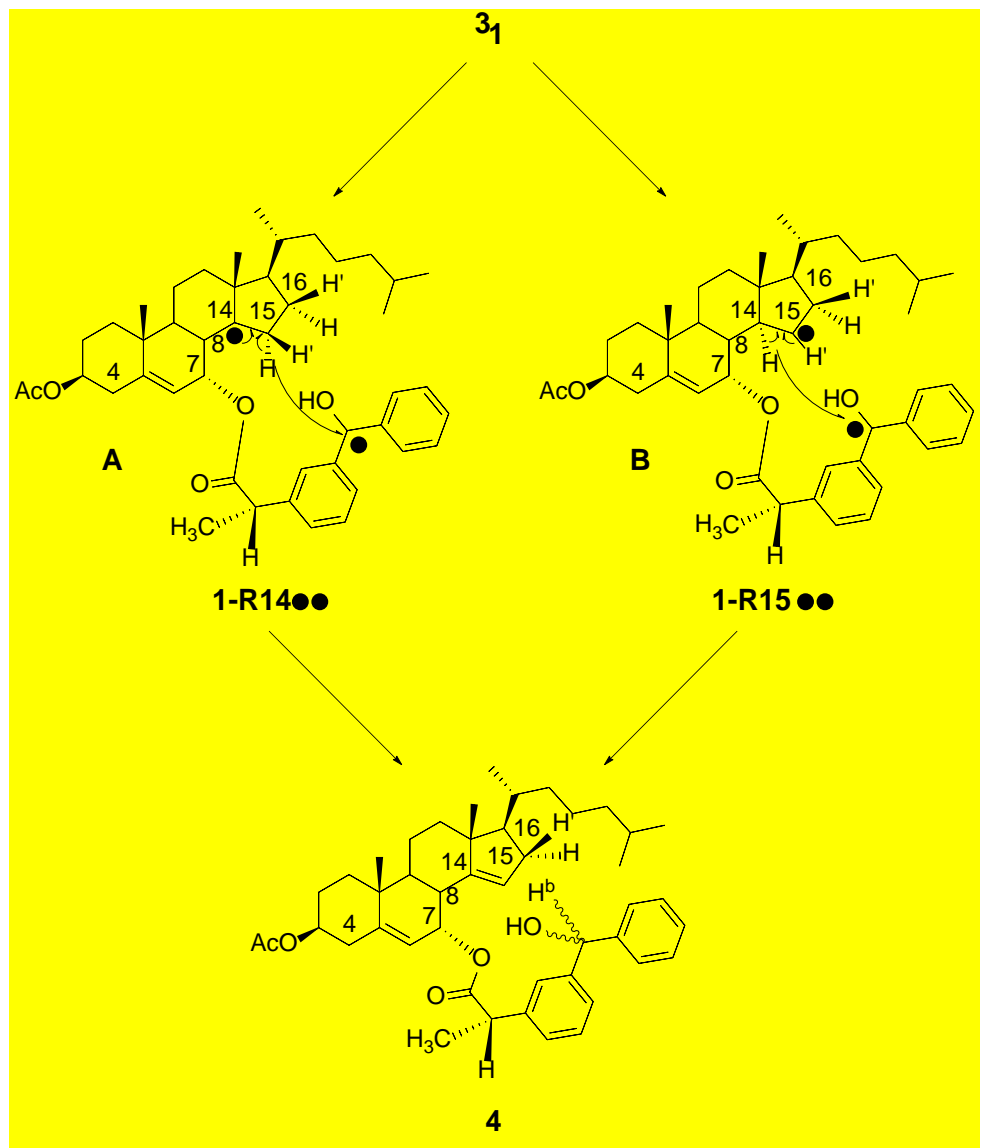

Scheme 3. Distinct reaction pathways to produce 4

211 While 3 is the result of the intramolecular hydrogen transfer from C4 carbon of the

212 steroid moiety, 4 can be formed via HA from C15 or C14 (Scheme 3). These reaction

213 pathways cannot be discriminated by product analysis and LFP. However, intermediate

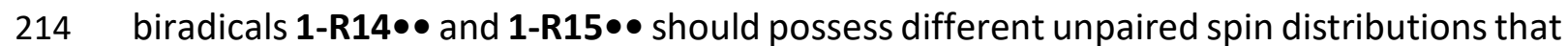

215 are reflected in different hyperfine couplings of protons in the molecules. This must lead

216 to different polarizations in CIDNP spectra. We have calculated hyperfine coupling

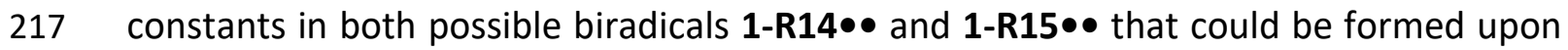

218 HA from C14 and C15 correspondingly. The results for the selected protons are shown

219 in the radar graph on the Figure 5. 


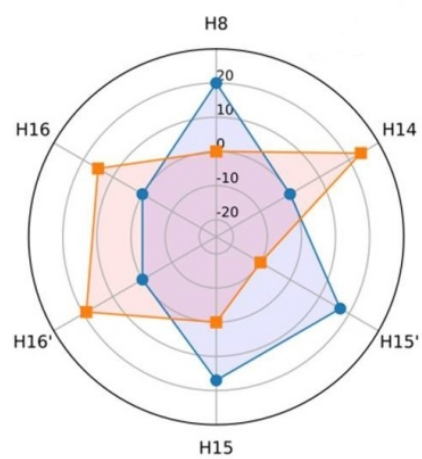

Figure 5 Calculated (B3LYP/TZVP) hfcs (in Gauss) of selected ${ }^{1} \mathrm{H}$ nuclei (for numbering, see Scheme 3 ) in biradicals 1-R14•• (dots, blue) and 1-R15•• (squares, orange)

Thus, it is clear that both biradicals have quite distinct hyperfine patterns. Hyperfine coupling constants that are plotted in Figure 5 are very different for matching protons in 1-R14•• and 1-R15•• (H8, H14, H15', H15, H16' and H16). In CIDNP spectrum upon irradiation of 1 polarizations of $\mathrm{H} 8, \mathrm{H} 16$ and $\mathrm{H} 16^{\prime}$ are overlapped with polarizations of different alkyl protons in parent $\mathbf{1}$ and/or in $\mathbf{3}$ and cannot be treated individually. In contrast, polarizations $\mathrm{H} 15$ and $\mathrm{Hb}\left(\mathrm{H} 15\right.$ and $\mathrm{H}_{15}$ in 1-R14••; $\mathrm{H} 14$ and $\mathrm{H} 15^{\prime}$ in 1-R15••) as we pointed out before, are clearly distinguishable (Figure 4).

There are two possible extreme cases in the photoreaction of 1 where $\mathbf{4}$ is exclusively formed via pathway A or B (Scheme 3). In the first case (path A) the ratio of the polarizations of $\mathrm{Hb}$ and $\mathrm{H} 15$ in $\mathbf{4}$ will be close to the ratio of the corresponding protons in 1-R14•• $\left(\mathrm{P}_{\mathrm{Hb}} / \mathrm{P}_{\mathrm{H} 15} \approx \mathrm{hfC}_{\mathrm{H} 15^{\prime}} / \mathrm{hfC}_{\mathrm{H} 15}=+17\right.$ Gauss/+17 Gauss $\left.=+1\right)$. Moreover, since both protons have hyperfine coupling constants of the same sign, their signals will be polarized in the same direction. In the second case (path B), all the CIDNP effect is generated in biradical $1-\mathbf{R} 15 \bullet \bullet$ and the ratio of the abovementioned polarizations will 
be $\mathrm{PHb} / \mathrm{P}_{\mathrm{H} 15} \approx \mathrm{hfC}{ }_{\mathrm{H} 14} / \mathrm{hfC}_{\mathrm{H} 15^{\prime}}=+24$ Gauss/-10 Gauss $=-2.4$ with opposite directions of polarization. If $\mathbf{4}$ is simultaneously produced via both pathways the ratio of polarizations will be determined by the superposition of these extreme scenarios. The $\mathrm{P}_{\mathrm{Hb}} / \mathrm{P}_{\mathrm{H} 15}$ measured from the CIDNP spectrum (Figure 4) is 2.5 , which is very close to the prediction

242 for the pathway B. This leads us to the conclusion that in dichloromethane 4 is produced solely via hydrogen abstraction from C15 on the timescale of the CIDNP experiment. This contrasts with the results obtained by Breslow and coworkers for other steroidal systems (although lacking the important unsaturation between C5 and C6). He showed the deuteration at position C15 of the steroid moiety, that the primary hydrogen abstraction takes place exclusively from C14. The difference in Breslow's benzophenone-coupled steroids is that linkers attached at the position $3 \alpha$ of the steroid core were not long enough for the ketone chromophore to reach the hydrogen atom at C15. In 1 the benzophenone moiety can get close to both C14 and C15; this explains HA from C15 but leaves the question as to such a high selectivity towards hydrogen transfer from C15 open. The photoproduct 3 that according to product analysis is formed alongside 4 by the HA from $\mathrm{C} 4$ and subsequent intramolecular recombination of biradical 1-R4••, should also manifest itself in the CIDNP spectrum of 1 . The "hyperfine

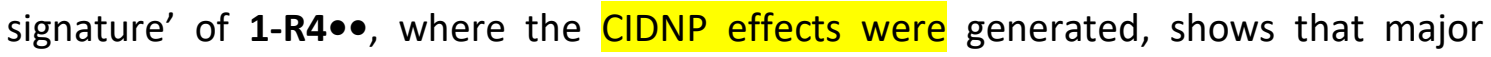
polarizations in $\mathbf{3}$ should stem from protons at carbons C3, C4, C6 and C7 of 1-R4•• since they possess the most prominent hyperfine coupling constants according to our quantum mechanical calculations (Figure 6). Unexpectedly, none of them apart from $\mathrm{H} 4$ (3.1 ppm) gives any significant polarization. This can be rationalized by the longer (relative to $1-\mathbf{R} 14 \bullet \bullet$ and $\mathbf{1 - R 1 5} \bullet \bullet$ ) lifetime of $\mathbf{1 - R 4 \bullet \bullet}$ and, possibly, shorter paramagnetic 

occurs.

264

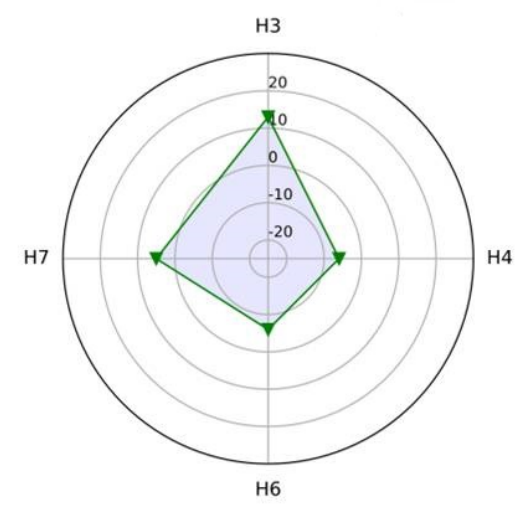

Figure 6. Calculated (B3LYP/TZVP) hfcs (in Gauss) of selected ${ }^{1} \mathrm{H}$ nuclei (for numbering, see Scheme 3) in biradical 1-R4••(green)

Dyad 2 did not show any CIDNP effects. This is in full agreement with the product analysis and can be understood in terms of the molecular structure. In $\mathbf{1}$, the benzophenone chromophore can adopt a conformation reaching $\mathrm{H} 4, \mathrm{H} 14$ and $\mathrm{H} 15$. This is not feasible in $\mathbf{2}$, where the benzophenone moiety resides above the steroid skeleton deflecting the ketone oxygen from those protons.

According to DFT calculations, the bond dissociation energy (BDE) of the secondary hydrogen at $\mathrm{C} 15$ is $\mathrm{ca} .26 \mathrm{~kJ} / \mathrm{mol}$ higher than that of $\mathrm{C} 14-\mathrm{H}$ (tertiary hydrogen). If only enthalpic control would rule the reactivity, the hydrogen transfer should exclusively happen from $\mathrm{C} 14$. The fact that we exclusively observe abstraction of $\mathrm{C} 15-\mathrm{H}$ reveals entropic/topologic factors being decisive for the hydrogen abstraction.

Solvation has a marked effect on the shape of flexible and polar molecules. ${ }^{29}$ In this respect, we performed (in addition to $\mathrm{CD}_{2} \mathrm{Cl}_{2}$ ) ${ }^{1} \mathrm{H}$ TR-CIDNP experiments in toluene- $\mathrm{d}_{8}$, 
281 from the CIDNP intensities determined from product 4 . Whereas in toluene the 282 hydrogen is almost exclusively abstracted from C15 (>90\%), the use of chloroform shifts 283 the ratio between $\mathrm{C} 14-\mathrm{H} / \mathrm{C} 15-\mathrm{H}$ to $1: 4$ and acetonitrile switches it to $2: 3$. These 284 observations are in line with a solvent-induced alteration of the preferred conformation of dyad 1.

Table 1. Contributions of HA from $\mathrm{C} 14$ and $\mathrm{C} 15$ into the formation of $\mathbf{4}$ from $\mathbf{1}$ in different solvents calculated from TR CIDNP spectra for details, see the Supporting Information).

\begin{tabular}{|c|c|c|c|}
\hline Solvent & $\begin{array}{l}\text { Polarity } \\
\text { index }\end{array}$ & $\begin{array}{l}\text { HA from } \\
\text { C14 (\%) }\end{array}$ & $\begin{array}{l}\text { HA from } \\
\text { C15 (\%) }\end{array}$ \\
\hline Toluene- $d_{8}$ & 2.4 & $<10$ & $>90$ \\
\hline $\mathrm{CD}_{2} \mathrm{Cl}_{2}$ & 3.1 & $<10$ & $>90$ \\
\hline $\mathrm{CDCl}_{3}$ & 4.1 & 20 & 80 \\
\hline $\mathrm{CD}_{3} \mathrm{CN}$ & 5.8 & 40 & 60 \\
\hline
\end{tabular}

Many biological reactions of cholesterol derivatives are ascribed to reactions in which hydrogen abstraction is involved. Our investigations on dyads $\mathbf{1}$ and $\mathbf{2}$ consisting of a $\mathbf{C h}$ core and benzophenone show that in addition to the thermodynamically favored $\mathrm{H}$ abstraction at $\mathrm{C} 4$, products and radicals based on HA from $\mathrm{C} 15$ take place. Such a regioselectivity is not observed in bimolecular reactions of $\mathbf{C h}$ and benzophenone in solution. This indicates that a specific orientation of the reactants is crucial for a site- 
selective reactivity of $\mathrm{Ch}$. A confined arrangement of the reactants is very likely to exist

297

298

299

300

301

302

303

304

305

306

307

308

309

310

311

312

313

314

315

in biological membranes containing $\mathbf{C h}$. Our observations are in agreement with clinical studies $^{16}$ pointing to the formation of $15 \alpha$-hydroxycholestene. Accordingly, our investigation reveals a specific topology being decisive for the reactivity in restricted (anisotropic) biological environments. Finally, selective activation of the strong $\mathrm{C} 15-\mathrm{H}$ bond in the presence of a weaker $\mathrm{C} 7-\mathrm{H}$ allylic bond is of great interest in the $\mathrm{C}-\mathrm{H}$ functionalization research.

\section{Experimental section}

\section{General}

AcetylCh and (S)-KP were commercially available. Other commercial reagents and solvents were used directly without further purification. One- $\left({ }^{1} \mathrm{H}\right.$ and $\left.{ }^{13} \mathrm{C}\right)$ and twodimensional (HSQC and NOESY) NMR spectra were recorded in $\mathrm{CDCl}_{3}$ as solvent on a Bruker AC-300; NMR chemical shifts are reported in ppm downfield from an internal solvent peak. All reactions were monitored by analytical TLC with silica gel 60 F254 revealed with ammonium molybdate reagent. The residues were purified through silica gel 60 (0.063-0.2 mm). Exact mass was obtained by TripleTOF ${ }^{\mathrm{TM}} 5600$ LC/MS/MS System, (AB SCIEX), equipped with an electrospray source. Thus, $7 \alpha-\mathrm{OH}$-acetylCh or $7 \beta-\mathrm{OH}-$ acetylCh were synthesized from acetylCh following procedures reported in previous publications. Their ${ }^{1} \mathrm{H}-\mathrm{NMR}$ and ${ }^{13} \mathrm{C}-\mathrm{NMR}$ signals coincide with those already described in the literature. ${ }^{31,32}$

\section{Synthesis of dyads 1 and 2}

To a solution of (S)-KP (215 mg, $0.84 \mathrm{mmol})$ in $\mathrm{CH}_{2} \mathrm{Cl}_{2}(5 \mathrm{~mL})$ dicyclohexylcarbodiimide (DCC, $320 \mathrm{mg}, 1.54 \mathrm{mmol}$ ) was added in small portions, and the mixture was stirred at 
$0^{\circ} \mathrm{C}$ for $30 \mathrm{~min}$. Then, a solution of $7 \alpha-\mathrm{OH}$-acetylCh or $7 \beta-\mathrm{OH}$-acetylCh $(340 \mathrm{mg}, 0.77$ $\mathrm{mmol}$ ) in $\mathrm{CH}_{2} \mathrm{Cl}_{2}(7 \mathrm{~mL}$ ) and 4-dimethylaminopyridine (DMAP, $10 \mathrm{mg}, 0.08 \mathrm{mmol}$ ) was added, and the mixture was kept under stirring overnight at the same temperature. The reaction mixture was then filtered through a pad of Celite ${ }^{\circledR}$. The resulting filtrate was washed with brine and water, dried over $\mathrm{Na}_{2} \mathrm{SO}_{4}$ and evaporated. The residue obtained was purified by column chromatography (eluent: dichloromethane-hexanedichloromethane acetate 90:5:5 v/v/v) to give dyad 1 (355 mg, $0.52 \mathrm{mmol}, 68 \%$ ) and dyad 2 (405 mg, $0.59 \mathrm{mmol}, 77 \%$ ).

(3S,7S,10R,13R,17R)-3-acetoxy-10,13-dimethyl-17-((R)-6-methylheptan-2-yl)2,3,4,7,8, 9,10,11,12,13,14,15,16,17-tetradecahydro-1H-cyclopenta[a]phenanthren-7-yl (2S)-2(3-benzoylphenyl)propanoate (1). ${ }^{1} \mathrm{H}-\mathrm{NMR}\left(300 \mathrm{MHz}, \mathrm{CDCl}_{3}\right) \delta=7.35-7.74(\mathrm{~m}, 9 \mathrm{H}, \mathrm{ArH})$, $5.48(\mathrm{~m}, 1 \mathrm{H}, \mathrm{C} 6-\mathrm{H}), 4.84(\mathrm{~m}, 1 \mathrm{H} ; \mathrm{C} 7-\mathrm{H}), 4.48(\mathrm{~m}, 1 \mathrm{H} ; \mathrm{C} 3-\mathrm{H}), 3.74\left(\mathrm{q}, J=7.2 \mathrm{~Hz}, 1 \mathrm{H} ; \mathrm{CH}_{3}-\right.$ $\mathrm{CH}-\mathrm{CO}), 2.25\left(\mathrm{~m}, 2 \mathrm{H} ; \mathrm{C} 4-\mathrm{H}_{2}\right), 1.96\left(\mathrm{~s}, 3 \mathrm{H} ; \mathrm{CH}_{3}\right.$ ), 0.98-1.94 (complex signal, 24H), 1.49 (d, $\left.J=7.2 \mathrm{~Hz}, 3 \mathrm{H} ; \mathrm{CH}_{3}\right), 0.91\left(\mathrm{~s}, 3 \mathrm{H} ; \mathrm{CH}_{3}\right), 0.82\left(\mathrm{~d}, J=6.6 \mathrm{~Hz}, 3 \mathrm{H} ; \mathrm{CH}_{3}\right), 0.80(\mathrm{~d}, J=6.6 \mathrm{~Hz}, 3 \mathrm{H}$; $\left.\mathrm{CH}_{3}\right), 0.79\left(\mathrm{~d}, \mathrm{~J}=6.6 \mathrm{~Hz}, 3 \mathrm{H} ; \mathrm{CH}_{3}\right), 0.54\left(\mathrm{~s}, 3 \mathrm{H} ; \mathrm{CH}_{3}\right) ;{ }^{13} \mathrm{C}\left\{{ }^{1} \mathrm{H}\right\}\left(75 \mathrm{MHz}, \mathrm{CDCl}_{3}\right) \delta=196.3$, $173.4,170.3,147.1,140.8,137.6,132.3,131.7,130.0,129.4,129.1,128.3,120.3,73.2$ $68.9,55.9,49.1,45.9,43.2,42.1,39.5,39.1,37.8,37.3,36.6,36.1,35.9,35.8,28.0,27.4$, 24.0, 22.8, 22.5, 21.3, 20.7, 18.7, 18.1, 17.9, 11.4. HRMS (EI): $\mathrm{m} / \mathrm{z}$ calcd for $\mathrm{C}_{45} \mathrm{H}_{61} \mathrm{O}_{5}$ $(\mathrm{M}+\mathrm{H})^{+}:$681.4514; found: 681.4492 .

(3S,7R,10R,13R,17R)-3-acetoxy-10,13-dimethyl-17-((R)-6-methylheptan-2yl)2,3,4,7,8, 9,10,11,12,13,14,15,16,17-tetradecahydro-1H-cyclopenta[a]phenanthren-7-yl (2S)-2(3-benzoylphenyl)propanoate (2). ${ }^{1} \mathrm{H}-\mathrm{NMR}\left(300 \mathrm{MHz}, \mathrm{CDCl}_{3}\right) \delta=7.18-7.82(\mathrm{~m}, 9 \mathrm{H} ; \mathrm{ArH})$; $5.24(\mathrm{~m}, 1 \mathrm{H} ; \mathrm{C} 6-H), 4.98(\mathrm{~m}, 1 \mathrm{H} ; \mathrm{C} 7-H), 4.61(\mathrm{~m}, 1 \mathrm{H} ; \mathrm{C} 3-H), 3.74\left(\mathrm{q}, J=7.2 \mathrm{~Hz}, 1 \mathrm{H} ; \mathrm{CH}_{3}-\right.$ 
$\mathrm{CH}-\mathrm{CO}$ ), 0.67-2.37 (complex signal, 29H), $2.05\left(\mathrm{~s}, 3 \mathrm{H} ; \mathrm{CH}_{3}\right), 1.55$ (d, J=7.2 Hz, 3H; $\mathrm{CH}_{3}$ ), 1.09 (s, 3H; $\left.\mathrm{CH}_{3}\right), 0.88\left(\mathrm{~d}, J=6.6 \mathrm{~Hz}, 3 \mathrm{H} ; \mathrm{CH}_{3}\right), 0.87\left(\mathrm{~d}, J=6.3 \mathrm{~Hz}, 3 \mathrm{H} ; \mathrm{CH}_{3}\right), 0.59(\mathrm{~s}, 3 \mathrm{H}$; $\left.\mathrm{CH}_{3}\right) ;{ }^{13} \mathrm{C}\left\{{ }^{1} \mathrm{H}\right\}\left(75 \mathrm{MHz}, \mathrm{CDCl}_{3}\right) \delta=196.4,173.8,170.3,144.5,140.6,137.7,137.6,132.4$, $131.8,130.0,129.7,129.0,128.4,128.3,122.0,73.2,55.4,53.4,48.2,45.7,42.7,39.5$, $39.3,38.2,37.6,36.5,36.4,36.3,36.1,35.7,31.2,30.9,29.7,28.0,27.6,25.1,23.8,22.8$, 22.5, 21.3, 21.1, 18.9, 18.6, 18.2, 11.7. HRMS (EI): $\mathrm{m} / \mathrm{z}$ calcd for $\mathrm{C}_{45} \mathrm{H}_{61} \mathrm{O}_{5}(\mathrm{M}+\mathrm{H})^{+}$: 681.4514; found: 681.4495 .

\section{Steady-state photolysis of dyads 1 and 2}

Deaerated dichloromethane $(40 \mathrm{~mL})$ solutions of 1 or $2(100 \mathrm{mg}, 0.15 \mathrm{mmol})$ were irradiated for $8 \mathrm{~h}$ through Pyrex with a $400 \mathrm{~W}$ medium pressure mercury lamp. After that, the reaction mixtures were concentrated under reduced pressure, and the photomixtures were submitted to silica gel column chromatography, using hexane/dichloromethane/ethyl acetate $(85: 10: 5 \mathrm{v} / \mathrm{v} / \mathrm{v})$ as eluent, affording the photoproducts 3 (23\%) and 4 (diastereomeric mixture, $25 \%$ ); the rest was mixture of several minor unidentified products, together with polymeric material. Moreover, to determine the photoreduction quantum yield of dyad 1 in dichloromethane, (S)-KP$3 \alpha-$ Ch was used as actinometer, with a quantum yield of $0.47 . .^{22}$ For this purpose, solutions of 1 and the actinometer were photolyzed under deaerated conditions using a multilamp photoreactor model LZC-4 (Luzchem, Canada) equipped with 8 lamps $\left(\lambda_{\max }\right.$ $=350 \mathrm{~nm}$, Gaussian distribution) and monitored by UV-spectrophotometry following the decrease in the absorption at $254 \mathrm{~nm}$. Thus, the quantum yield was calculated from the slope of the plot absorbance at $254 \mathrm{~nm}$ versus irradiation time. 
(3R,3aR,5aS,6R,9S,17S,20S)-3[(1R)-1,5-dimethylhexyl]1,2,3,3a,4,5,5a,6,7,8,9,10,11,

20,20a,21-hexadecahydro-11-hydroxy-7a,6,17trimethyl-11-phenyl-20,6,10-etheno-

12,16-methenoindeno[5,4f]oxacycloheptadecin-18(17H)-one (3). ${ }^{1} \mathrm{H}-\mathrm{NMR}(300 \mathrm{MHz}$, $\left.\mathrm{CDCl}_{3}\right) \delta=7.71(\mathrm{~m}, 1 \mathrm{H} ; \mathrm{ArH}), 7.22-7-39(\mathrm{~m}, 6 \mathrm{H} ; \mathrm{ArH}), 7.12(\mathrm{~m}, 1 \mathrm{H} ; \mathrm{ArH}), 6.51(\mathrm{~s}, 1 \mathrm{H} ; \mathrm{ArH})$, $5.47(\mathrm{~d}, J=5.1 \mathrm{~Hz}, 1 \mathrm{H} ; \mathrm{C} 6-H), 4.53(\mathrm{~m}, 1 \mathrm{H} ; \mathrm{C} 7-H), 4.47(\mathrm{~m}, 1 \mathrm{H} ; \mathrm{C} 3-H), 3.70(\mathrm{q}, J=7.5 \mathrm{~Hz}$, $\left.1 \mathrm{H} ; \mathrm{CH}_{3}-\mathrm{CH}-\mathrm{CO}\right), 3.05(\mathrm{~m}, 1 \mathrm{H} ; \mathrm{C} 4-\mathrm{H}), 2.22\left(\mathrm{~m}, 2 \mathrm{H} ; \mathrm{C} 2-\mathrm{H}_{2}\right), 1.95\left(\mathrm{~s}, 3 \mathrm{H} ; \mathrm{CH}_{3}\right), 0.42-1.90$ (complex signal, 22H), $1.46\left(\mathrm{~d}, J=7.5 \mathrm{~Hz}, 3 \mathrm{H} ; \mathrm{CH}_{3}\right.$ ), 1.07 (d, J = 7.2 Hz, 3H; $\mathrm{CH}_{3}$ ), 0.84 (s, $\left.3 \mathrm{H} ; \mathrm{CH}_{3}\right), 0.81\left(\mathrm{~d}, J=6.6 \mathrm{~Hz}, 6 \mathrm{H} ; 2 \times \mathrm{CH}_{3}\right), 0.60\left(\mathrm{~s}, 3 \mathrm{H} ; \mathrm{CH}_{3}\right),-0.45(\mathrm{~m}, 1 \mathrm{H} ; \mathrm{CH}) ;{ }^{13} \mathrm{C}\left\{{ }^{1} \mathrm{H}\right\}(75$ $\left.\mathrm{MHz}, \mathrm{CDCl}_{3}\right) \delta=175.6,170.4,148.1,146.9,143.2,138.7,130.0,129.8,128.4,128.3$ $128.1,127.8,126.8,126.4,122.7,120.4,82.1,73.2,69.1,55.9,45.7,44.0,43.9,43.7$, $42.9,39.4,38.4,37.6,37.2,36.4,36.3,35.3,32.5,30.8,28.1,27.4,26.2,22.8,22.7,21.3$, 20.6, 20.0, 17.9, 14.3, 14.2. HRMS (EI): $\mathrm{m} / z$ calcd for $\mathrm{C}_{45} \mathrm{H}_{61} \mathrm{O}_{5}(\mathrm{M}+\mathrm{H})^{+}:$: 681.4514; found: 681.4518.

\section{(3S,7R,10R,13R,17R)-3-acetoxy-10,13-dimethyl-17-((R)-6-methylheptan-2-yl)-2,3,4,7,}

\section{$8,9,10,11,12,13,16,17-d o d e c a h y d r o-1 H-c y c l o p e n t a[a] p h e n a n t h r e n-7-y l(2 S)-2-(3-$}

(hydroxy(phenyl)methyl)phenyl)propanoate (4, diastereomeric mixture). ${ }^{1} \mathrm{H}-\mathrm{NMR}$ $\left(300 \mathrm{MHz}, \mathrm{CDCl}_{3}\right) \delta=7.08-7.32(\mathrm{~m}, 9 \mathrm{H} ; \mathrm{ArH}), 5.73(\mathrm{~m}, 1 \mathrm{H} ; \mathrm{Ph}-\mathrm{CH}-\mathrm{OH}), 5.47(\mathrm{~m}, 1 \mathrm{H} ; \mathrm{C} 6-$ H), $5.12(\mathrm{~m}, 1 \mathrm{H} ; \mathrm{C} 15-H), 4.90(\mathrm{~m}, 1 \mathrm{H} ; \mathrm{C} 7-H), 4.36(\mathrm{~m}, 1 \mathrm{H} ; \mathrm{C} 3-H), 3.64(\mathrm{q}, J=7.2 \mathrm{~Hz}, 1 \mathrm{H}$; $\left.\mathrm{CH}_{3}-\mathrm{CH}-\mathrm{CO}\right), 2.94(\mathrm{~m}, 1 \mathrm{H} ; \mathrm{C} 4-\mathrm{H}), 2.82(\mathrm{~m}, 1 \mathrm{H} ; \mathrm{C} 4-\mathrm{H}), 0.56-2.28$ (complex signal, $35 \mathrm{H}$ ), $1.95\left(\mathrm{~d}, J=1.8 \mathrm{~Hz}, 3 \mathrm{H} ; \mathrm{CH}_{3}\right), 0.79\left(\mathrm{~d}, J=6.6 \mathrm{~Hz}, 3 \mathrm{H} ; \mathrm{CH}_{3}\right), 0.78\left(\mathrm{~d}, J=6.6 \mathrm{~Hz}, 3 \mathrm{H} ; \mathrm{CH}_{3}\right)$, 0.67 (s, 3H; $\left.\mathrm{CH}_{3}\right) ;{ }^{13} \mathrm{C}\left\{{ }^{1} \mathrm{H}\right\}\left(75 \mathrm{MHz}, \mathrm{CDCl}_{3}\right) \delta=174.0,173.9,170.8,170.7,160.5,160.4$, $146.9,146.8,144.4,144.3,144.1,140.7,139.3,128.6,128.5,128.4,128.3,127.4,127.3$ 127.0, 126.6, 126.5, 125.6, 125.5, 125.2, 125.1, 120.6, 120.5, 120.4, 120.3, 114.1, 76.0, 

21.4, 20.5, 18.1, 17.7, 17.5, 15.8, 14.1. HRMS (EI): $\mathrm{m} / \mathrm{z}$ calcd for $\mathrm{C}_{45} \mathrm{H}_{61} \mathrm{O}_{5}(\mathrm{M}+\mathrm{H})^{+}$: 681.4514; found: 681.4507.

\section{Laser flash photolysis measurements}

392

393

A pulsed Nd:YAG laser was used for excitation at $355 \mathrm{~nm}$. The single pulse was $10 \mathrm{~ns}$ duration and the energy raning from 10 to $1 \mathrm{~mJ}$ pulse ${ }^{-1}$. The LFP system consisted of the pulsed laser, the Xe lamp, a monochromator and a photomultiplier made up of a tube, housing and power supply. The output signal from the oscilloscope was transferred to a personal computer. All experiments were performed at room temperature under anaerobic conditions. The samples were dissolved in dichloromethane to have an absorbance ca. 0.30 at $355 \mathrm{~nm}$.

\section{CIDNP and quantum mechanical calculations of hyperfine coupling constants}

${ }^{1} \mathrm{H}$ CIDNP spectra were recorded on a $200 \mathrm{MHz}$ Bruker AVANCE DPX spectrometer. Irradiation was carried out by using a frequency-tripled Quantel Nd:YAG Brilliant B laser (10 Hz, $355 \mathrm{~nm}, \mathrm{ca} .90 \mathrm{~mJ}$ per pulse, pulse width ca. $8 \mathrm{~ns}$ ). The following pulse sequence was used: presaturation (waltz16) - laser flash - RF detection pulse $(2 \mu \mathrm{s})$ - free induction decay. Dark spectra (background) - the same sequence without the laser flash - were always recorded to assure the effective suppression of background NMR signals. The concentrations of 1 and $\mathbf{2}$ were $0.01 \mathrm{M}$. To exclude oxygen, samples were bubbled with Argon for 5 minutes prior to experiments. Hyperfine coupling constants of free radicals were calculated using the Gaussian $09^{33}$ package. All calculations (geometry 
optimizations and single-point calculations) were conducted at the B3LYP ${ }^{34,35}$ level of 410 theory with the TZVP ${ }^{36}$ basis set.

411 Calculation of the contributions of $1-\mathrm{R} 14 \bullet \bullet$ and $1-\mathrm{R} 15 \bullet \bullet$ biradicals into CIDNP

412

413

414

415

416

417

418

419

420 polarizations of $\mathrm{H} 15$ and $\mathrm{Hb}$ protons.

Polarizations of $\mathrm{Hb}\left(\mathrm{P}_{\mathrm{Hb}}\right)$ and $\mathrm{H} 15\left(\mathrm{P}_{\mathrm{H} 15}\right)$ can be measured directly from the spectrum and their ration is:

$$
\frac{P_{H b}}{P_{H 10}}=-2.4
$$

Polarization of $\mathrm{Hb}$ is constructed from contributions of $1-\mathrm{R} 14 \bullet \bullet$ and $1-\mathrm{R} 15 \bullet \bullet$ which are proportional to hyperfine coupling constants of corresponding protons in those biradicals and:

$$
P_{H b}=C \times a_{H 14}^{R 15}+(1-C) \times a_{H 15}^{R 14}
$$

Where $a_{H 14}^{R 15}$ and $a_{H 15}^{R 14}$ are hiperfine coupling protons $\mathrm{H} 14$ and H15 in biradicals 1-R15•• and 1-R14•• correspondingly. Analogously the polarization of H15 is represented:

$$
P_{H 15}=C \times a_{H 15}^{R 15}+(1-C) \times a_{H 15}^{R 14}
$$

The system of equations 1-3 can be solved with respect to proportionality constant C which gives us contributions of 2 different biradicals into CIDNP polarizations.

\section{Associated content}

\section{Supporting Information}

The Supporting Information is available free of charge on the...

Scheme of the synthesis of dyads 1 and 2 (Scheme S1); ${ }^{1} \mathrm{H}$ and ${ }^{13} \mathrm{C}-\mathrm{NMR}$ spectra of 7oxo-acetylCh; ${ }^{1 \mathrm{H}}$ and ${ }^{13} \mathrm{C}-\mathrm{NMR}$ spectra of $7 \alpha-\mathrm{OH}$-acetylCh; ${ }^{1} \mathrm{H}$ and ${ }^{13} \mathrm{C}-\mathrm{NMR}$ spectra of 


\section{Acknowledgements}

This work was supported by the Carlos III Institute of Health (Grants: PI16/01877, exchange student (M.B) DN and GG thank NAWI Graz for support.

\section{References}

1 Zerbinati, C., Iuliano L. Cholesterol and related sterols autoxidation. Free Radic. Biol. Med. 2017, $111,151-155$.

2 Schroepfer, G. J. Oxysterols: modulators of cholesterol metabolism and other processes. Physiol. Rev. 2000, 80, 361-554.

3 Girotti, A. W., Korytowski, W. Cholesterol hydroperoxide generation, translocation, and reductive turnover in biological systems. Cell Biochem. Biophys. 2017, 75, 413-419.

4 Poli, G., Biasi, F., Leonarduzzi, G. Oxysterols in the pathogenesis of major chronic diseases. Redox Biol. 2013, 1, 125-130.

5 Buttari, B., Segoni, L., Profumo, E., D’Arcangelo, D., Rossi, S., Facchiano, F., Businaro, R., luliano, macrophages. Biochem. Pharmacol. 2013, 86, 130-137.

6 Scheinost, J. C., Wang, H., Boldt, G. E., Offer, J., Wentworth, P. Cholesterol seco-sterol-induced aggregation of methylated amyloid-beta peptides--insights into aldehyde-initiated fibrillization of 
7 Shahidi, F., Zhong, Y. Lipid oxidation and improving the oxidative stability. Chem. Soc. Rev. 2010, 39, 4067-4079.

8 Zielinski, Z. A. M., Pratt, D.A. Lipid peroxidation: kinetics, mechanisms, and products. J. Org. Chem. $2017,82,2817-2825$.

9 Sarzi-Puttini, P., Atzeni, F., Lanata, L., Bagnasco, M. Efficacy of ketoprofen vs. ibuprofen and diclofenac: a systematic review of the literature and meta-analysis. Clin. Exp. Rheumatol. 2013, $31,731-738$.

10 Bignon, E., Marazzi, M., Besancenot, V., Gattuso, H., Drouot, G., Morell, C., Eriksson, L. A., Grandemange, S., Dumont, E., Monar, A. Ibuprofen and ketoprofen potentiate UVA-induced cell death by a photosensitization process. Sci. Rep. 2017, 7, 8885 .

11 Bagheri, H., Lhiaubet, V., Montastruc, J. L., Chouini-Lalanne, N. Photosensitivity to ketoprofen: mechanism and pharmacoepidemiological data. Drug Saf. 2000, 22, 339-349.

12 Breslow, R. Biomimetic control of chemical selectivity. Acc. Chem. Res. 1980, 13, 170-177. steroids by photolysis of attached benzophenone groups. J. Am. Chem. Soc. 1973, 95, 3251-3262.

14 Zielinski, Z. A. M., Pratt, D. A. Cholesterol autoxidation revisited: debunking the dogma associated with the most vilified of lipids J. Am. Chem. Soc. 2016, 138, 6932-6935.

15 Garrec, J., Monari A., Assfeld, X., Mir, L. M., Tarek, M. Lipid peroxidation in membranes: the peroxyl radical does not "float". J. Phys. Chem. Lett. 2014, 5, 1653-1658.

16 Farez, M., Quintana, F. J., Gandhi, R., Izquierdo, G., Lucas M., Weiner, H. L. Toll-like receptor 2 and poly(ADP-ribose) polymerase 1 promote central nervous system neuroinflammation in progressive EAE. Nat. Immunol. 2009, 10, 958-964.

17 Björkhem, I., Lövgren-Sandblom, A., Piehl, F., Khademi, M., Pettersson, H., Leoni, V., Olsson, T., Diczfalusy, U. High levels of 15-oxygenated steroids in circulation of patients with multiple sclerosis: fact or fiction? J. Lipid Res. 2011, 52, 170-174.

18 Davies, H., Morton, D. Collective approach to advancing C-H functionalization. ACS Cent. Sci. 2017, 3, 936-943.

19 Gutekunst, W. R., Baran, P. Applications of C-H functionalization logic to cyclobutane synthesis. 
20 Neshchadin, D., Palumbo, F., Sinicropi, M. S., Andreu, I., Gescheidt, G., Miranda, M. A. Topological control in radical reactions of cholesterol in model dyads. Chem. Sci. 2013, 4, 1608-1614.

21 Andreu, I., Morera, I. M., Boscá, F., Sanchez, L., Camps, P., Miranda, M. A. Cholesterol-diaryl ketone stereoisomeric dyads as models for "clean" type I and type II photooxygenation mechanisms. Org. Biomol. Chem. 2008, 6, 860-867.

22 Andreu, I., Palumbo, F., Tilocca, F., Morera, I. M., Bosca, F., Miranda, M. A. Solvent effects in hydrogen abstraction from cholestrol by benzophenone triplet excited state. Org. Lett. 2011, 13, 4096-4099.

23 Bosca, F., Andreu, I., Morera, I. M., Samadi, A., Miranda, M. A. Chiral discrimination in the intramolecular abstraction of allylic hydrogens by benzophenone triplets. Chem. Commun. 2003, 1592-1593.

24 Kaptein, R., Oosterhoff, L. J. Chemically induced dynamic nuclear polarization III (anomalous 496 multiplets of radical coupling and disproportionation products). Chem. Phys. Lett. 1969, 4, 214216.

25 Closs, G. L. Mechanism explaining nuclear spin polarizations in radical combination reactions. J. Am. Chem. Soc. 1969, 91, 4552-4554.

26 Vollenweider, J. K., Fischer, H., Hennig, J., Leuschner, R. Time-resolved CIDNP in laser flash photolysis of aliphatic ketones. A quantitative analysis. Chem. Phys. 1985, 97, 217-234.

27 Neshchadin, D., Levinn, R., Gescheidt, G., Batchelor, S.N. Probing the antioxidant activity of polyphenols by CIDNP: from model compounds to green tea and red wine. Chem. - A Eur. J. 2010, 16, 7008-7016.

28 Yurkovskaya, A., Morozova, O., Gescheidt, G. Encycl. Radicals Chem. Biol. Mater. (John Wiley \& Sons, Ltd, Chichester, UK, 2012) 930-933. 
50931 Poza, J., Rega, M., Paz, V., Alonso, B., Rodríguez, J., Salvador, N., Fernández, A., Jiménez, C. 510 Synthesis and evaluation of new 6-hydroximinosteroid analogs as cytotoxic agents. Bioorg. Med. $511 \quad$ Chem. 2007, 15, 4722-4740.

51232 Poza, J. J., Jiménez, C., Rodríguez, J. J-Based Analysis and DFT-NMR Assignments of Natural 513 Complex Molecules: Application to 3ß,7-Dihydroxy-5,6-epoxycholestanes. Eur. J. Org. Chem. $514 \quad 2008,23,3960-3969$.

51533 Frisch, M. J., Trucks, G. W., Schlegel, H. B., Scuseria, G. E., Robb, M. A., Cheeseman, J. R., Scalmani, 516 G., Barone, V., Mennucci, B., Petersson, G. A. et al. Gaussian 09, Revision D.01. Gaussian, Inc.: 517 Wallingford, CT, USA, 2009.

51834 Stephens, P. J., Devlin, F. J., Chabalowski, C. F., Frisch, M. J. J. Phys. Chem. 1994, 98, $11623-11627$.

51935 Becke, A. D. J. Chem. Phys. 1993, 98, 5648-5652.

52036 Schäfer, A., Horn, H., Ahlrichs, R. J. Chem. Phys. 1992, 97, 2571-2577.

521 